\title{
Continuous lumbar transversus abdominis plane block may spread to supraumbilical dermatomes
}

\section{Les blocs lombaires continus du plan transverse de l'abdomen pourraient diffuser vers les dermatomes sus-ombilicaux}

\author{
Mauricio Forero, MD • Victor M. Neira, MD • \\ Andrew J. Heikkila, MD · James E. Paul, MD
}

Received: 27 April 2011/Accepted: 28 June 2011/Published online: 12 July 2011

(c) Canadian Anesthesiologists' Society 2011

\begin{abstract}
Purpose The transversus abdominis plane block is an interfascial block intended to target nerves supplying the abdominal wall. It has been shown to reduce pain and postoperative opioids in abdominal surgeries. We present the case of a high-risk patient in whom bilateral continuous lumbar transversus abdominis plane blocks provided effective postoperative analgesia following infraumbilical midline laparotomy.

Clinical features A 59-yr-old woman with coronary artery disease, severe peripheral vascular disease, and mild to moderate obstructive sleep apnea underwent a total abdominal hysterectomy, bilateral salpingo-oophorectomy, and pelvic lymph node dissection via an infraumbilical midline laparotomy. Bilateral ultrasound-guided lumbar transversus abdominis plane blocks with catheters were sited intraoperatively. Using only a continuous local anesthetic infusion in the postoperative period, the patient required no systemic opioids or acetaminophen for $81 \mathrm{hr}$. A sensory block level of T6-L1, higher than that reported following a single-shot technique, remained for $24 \mathrm{hr}$ following infusion discontinuation and finally normalized after $33 \mathrm{hr}$.
\end{abstract}

\footnotetext{
M. Forero, MD ( $\square)$

Department of Anesthesia, St. Joseph's Healthcare, McMaster University, 50 Charlton Avenue East, Hamilton, ON L8N 4A6, Canada

e-mail: foreroc@mcmaster.ca
}

V. M. Neira, MD

Department of Anesthesia, Children's Hospital of Eastern Ontario, University of Ottawa, Ottawa, ON, Canada

\author{
A. J. Heikkila, MD · J. E. Paul, MD \\ Department of Anesthesia, McMaster University Medical \\ Centre, McMaster University, Hamilton, ON, Canada
}

Conclusions Lumbar transversus abdominis plane blocks with continuous infusions may offer an effective alternative to epidural blockade and systemic opioids in high-risk patients. Additionally, given the extensive somatosensory block, this technique may have an analgesic role following abdominal incisions involving not only the infraumbilical region but also supraumbilical sites.

\section{Résumé}

Objectif Le bloc du plan transverse de l'abdomen est un bloc interfascial qui cible les nerfs innervant la paroi abdominale. Il a été démontré qu'il réduisait la douleur et les besoins postopératoires en opioïdes lors d'une chirurgie abdominale. Nous présentons le cas d'une patiente à risque élevé chez qui des blocs lombaires continus du plan transverse de l'abdomen ont procuré une analgésie postopératoire efficace après une laparotomie sous-ombilicale médiane.

Éléments cliniques Une femme de 59 ans souffrant de maladie coronarienne, de maladie vasculaire périphérique grave et d'apnée du sommeil obstructive légère à modérée a subi une hystérectomie abdominale totale, une salpingo-ovariectomie et un évidement ganglionnaire pelvien par laparotomie sous-ombilicale médiane. Des blocs bilatéraux lombaires échoguidés du plan transverse de l'abdomen ont été positionnés pendant l'opération. En utilisant seulement une perfusion d'anesthésique local en période postopératoire, la patiente n'a pas eu besoin d'opioïles systémiques ou d'acétaminophène pendant 81 h. Un bloc sensitif au niveau T6-L1, plus haut que celui rapporté après une technique à injection unique, s'est maintenu pendant $24 \mathrm{~h}$ après l'interruption de la perfusion, puis s'est finalement normalisé après $33 \mathrm{~h}$.

Conclusion Les blocs lombaires du plan transverse de l'abdomen suivis de perfusions continues pourraient 
constituer une alternative efficace aux blocs périduraux et aux opioïles systémiques chez les patients à risque élevé. En outre, étant donné l'étendue importante du bloc somatosensoriel, cette technique pourrait jouer un rôle analgésique après des incisions abdominales réalisées non seulement dans la région sous-ombilicale, mais également dans les zones sus-ombilicales.

The lumbar transversus abdominis plane (TAP) block is a novel technique which targets nerves supplying the abdominal wall. The objective of the block is to inject local anesthetic into the TAP, a potential space between the internal oblique and transversus abdominis muscles, and thereby block eight spinal nerves that innervate the abdominal muscles and overlying skin. The block can be performed using surface landmarks using a "double-pop" technique, but ultrasound (US) guidance is becoming increasingly popular as it enables real-time direct visualization of the relevant muscle layers and the location of the injected local anesthetic. Although the evidence is limited to date, a recent meta-analysis of randomized trials of abdominal surgery and the TAP block involving five studies and 236 patients showed that this technique reduced morphine consumption at 24 and $48 \mathrm{hr} .{ }^{1}$ Further studies are necessary to compare this block with other regional techniques like epidural analgesia and local infiltration. Recently, the use of TAP blocks with indwelling catheters has been described in the literature with promising results. ${ }^{2}$ We report a somatosensory block by loss to cold sensation and successful postoperative pain management for a patient with several cardiorespiratory comorbidities. The procedure was performed by way of US-guided bilateral lumbar TAP blocks with continuous local anesthetic infusions. Written informed consent and institutional ethics board approval were obtained prior to publication of this case.

\section{Case description}

A 59-yr-old female with stage II endometrial adenocarcinoma was scheduled to undergo total abdominal hysterectomy, bilateral salpingo-oophorectomy, and removal of left-pelvic sidewall lymph nodes via an infraumbilical midline laparotomy.

Her cardiovascular history was remarkable for hypertension, type II diabetes mellitus, and severe coronary and peripheral artery disease. She had a previous myocardial infarction, coronary artery bypass grafting, and percutaneous angioplasty with stenting. Her cardiovascular status was currently stable without angina or dyspnea, and her condition was optimized with medical therapy. Her severe peripheral vascular disease had required bilateral lower limb amputations. The most recent amputation was complicated by a Methicillin-resistant Staphylococcus aureus stump infection and an infected common femoral artery graft. Other comorbidities included diabetic retinopathy and nephropathy, obesity (body mass index $=40 \mathrm{~kg} \cdot \mathrm{m}^{-2}$ ), and untreated obstructive sleep apnea (OSA) with an apnea/hypopnea index of 14.3 and occasional severe desaturations.

A preoperative echocardiogram demonstrated extensive anteroapical akinesis and hypokinesis of the inferior wall, moderate diastolic dysfunction, and systolic function compromise (ejection fraction $=40 \%$ ). Single photon emission computed tomography (SPECT) with dipyridamole stress showed evidence of previous transmural anteroseptal and apical infarction without evidence of current ischemia. The patient's baseline serum creatinine was $140 \mathrm{mg} \cdot \mathrm{L}^{-1}$. Her medications included ramipril, atorvastatin, acetylsalicylic acid, bisoprolol, clopidogrel (on hold for surgery), furosemide, gabapentin, hydromorphone contin, metformin, insulin aspart, detemir, risedronate, vancomycin, moxifloxacin, and domperidone.

The intraoperative and postoperative plans were discussed with the surgical team, and we decided to perform bilateral TAP blocks with indwelling catheters and continuous local anesthetic infusion for postoperative analgesia. We elected to proceed in this fashion to avoid epidural sympathetic blockade and the associated complications linked to hypotension in this high-risk patient. Furthermore, this technique could reduce postoperative opioid use, an attractive option given the patient's untreated OSA.

We applied standard American Society of Anesthesiologists (ASA) anesthesia monitors plus a pre-induction right radial arterial line. General anesthesia was induced using fentanyl, propofol, and rocuronium. The patient's trachea was intubated, anesthesia was maintained with desflurane, and surgery proceeded as planned. Morphine $3 \mathrm{mg} i v$ was given $30 \mathrm{~min}$ before the end of surgery, and non-steroidal anti-inflammatory drugs were avoided in light of the patient's diabetic nephropathy.

We performed US-guided lumbar TAP blocks at the end of the operation while the patient was still anesthetized. Under sterile technique, a $12 \mathrm{MHz}$ linear US transducer (GE Logiq E, Wauwatosa, WI, USA) was placed cephalad between the inferior costal margin and anterior superior iliac spine in the anterior-axillary line. A 17G Tuohy needle (Smiths Medical Portex ${ }^{\circledR}$ epidural mini-pack, St. Paul, MN, USA) was advanced using an in-plane approach from medial to lateral and placed between the internal oblique and transversus abdominis muscles. Hydro-dissection was used to confirm proper needle tip position prior 
to slow injection of $0.5 \%$ ropivacaine $20 \mathrm{~mL}$. Following this, a $20 \mathrm{G}$ epidural catheter was advanced $5 \mathrm{~cm}$ distal to the needle tip without resistance. The needle was then removed and the catheter secured using a clear occlusive dressing. The identical procedure was then performed on the opposite side. The patient's trachea was extubated, and she was then transferred to a monitored recovery area for the next four hours. She reported pain scores of 0 (out of 10) at rest and during movement in the postanesthesia care unit, and in fact, she requested to be placed in a seated position. She did report nausea, which was controlled with ondansetron and dimenhydrinate. Orders were written for gabapentin $300 \mathrm{mg}$ tid, acetaminophen $975 \mathrm{mg}$ qid prn, and morphine prn for breakthrough pain.

The patient was discharged to the step-down unit asymptomatic and in stable cardiorespiratory condition. She was followed by the Acute Pain Service (nurses/consultants) for a total of $72 \mathrm{hr}$, with her pain scores and block height evaluated every four hours. The first sensory assessment was performed seven hours following surgery. The abdominal wall dermatomes were outlined with a marking pen to allow for consistent assessments by different evaluators. A continuous infusion of $0.125 \%$ bupivacaine at $5 \mathrm{~mL} \cdot \mathrm{hr}^{-1}$ per side using separate infusion pumps (Cardinal Health, Alaris ${ }^{\circledR}$ PCA Module, Model 8120, San Diego, CA, USA) was started in the recovery room and continued for $48 \mathrm{hr}$. The block extension, as measured by loss to cold sensation, was consistently T6-L1 bilaterally until $72 \mathrm{hr}$, with regression to T10-L1 at $76 \mathrm{hr}$ and finally only a bilateral T12 block at $81 \mathrm{hr}$. Gabapentin tid was provided in the postoperative period, but morphine and acetaminophen were never requested by the patient. The patient was discharged home at $72 \mathrm{hr}$ in stable condition, and a home visit made that night showed that the patient was continuing to recover well.

\section{Discussion}

This report is novel in its detailing of the somatosensory block extension characteristics following continuous bilateral lumbar TAP blocks from initiation to the hours following catheter removal. This report highlights the effectiveness of providing post-laparotomy analgesia with continuous lumbar TAP blocks in a high-risk patient with cardiorespiratory disease.

Pain after extensive abdominal surgery is typically classified as severe pain. Current trends in postoperative pain management after laparotomy include epidural analgesia and/or patient controlled analgesia (PCA) with opioids. The secondary effects of such strategies include hypotension and respiratory depression, respectively, and they have the potential to complicate the perioperative course in high-risk patients with cardiorespiratory disease.

The TAP block was first described by $\operatorname{Rafi}^{3}$ as a blind "double-pop" technique through the Petit triangle. Hebbard ${ }^{4}$ introduced the US-guided TAP technique six years later. Ultrasound-guided TAP blocks have the advantage of real-time performance, and they are particularly useful in obese patients in whom the blind technique is technically difficult. An additional advantage of the US-guided technique is that it may decrease complication rates, such as hepatic injuries, previously described with the blind technique. ${ }^{5}$ Prolonged TAP blocks using indwelling catheters and continuous local anesthetic infusions have been described in a few cases, i.e., for postoperative pain management in renal transplant recipients, abdominal midline surgical incisions, and inguinal hernia repairs, with promising results. ${ }^{2,6,7}$

The TAP block is an interfascial block, and the target nerves cannot be visualized under US. The nerve distribution in the plane has been previously described in cadaveric dissections, and these studies suggest that lumbar blocks would be more appropriate for lower abdominal surgeries. Injection of aniline blue $20 \mathrm{~mL}$ into the lumbar TAP is likely to involve only the T10-L1 nerve roots, implying that the lumbar technique is best suited for infraumbilical incisions. ${ }^{89}$ Subcostal TAP blocks, described by Hebbard, ${ }^{10}$ are thought to target higher dermatomes, making it a better option for supraumbilical incisions.

Despite the cadaveric studies, debate remains with respect to the somatosensory block height that can be achieved with a single local anesthetic injection at the lumbar TAP level. McDonnell ${ }^{11}$ reported a T7-L1 sensory block using $0.5 \%$ lidocaine on three volunteers, while Shibata $^{12}$ found a maximum block height of only T9. This discrepancy persists largely because no studies have assessed block height as a primary outcome. In fact, none of the five TAP block randomized control trials have tested dermatome block extension. ${ }^{1}$

Since the TAP block is a compartmental block, it is likely to be affected by multiple variables, including local anesthetic volume, concentration, infusion time, and site of injection. Patient factors, including height and weight, are also likely to contribute. Large studies are required to address these questions.

This case describing the use of bilateral lumbar TAP blocks with indwelling catheters suggests the feasibility of this approach as an alternative to epidural anesthesia and PCA. Not only does this technique serve to benefit patients with cardiorespiratory comorbidities, it would benefit patients with coagulation disorders in whom neuraxial anesthesia is contraindicated. In our case, the patient required no opioids in the postoperative period, which was optimal given her OSA history. The lack of postoperative 
opioids is interesting in that TAP blocks are believed to block only somatic components and the parietal peritoneum. In this case, a component of visceral blockade might be caused by a systemic rather than a local analgesic effect of the local anesthetic, as previously suggested. ${ }^{13}$ This positive outcome with a TAP block for gynecological cancer surgery contrasts with the results recently published from a randomized trial of 65 patients who received a TAP block or placebo for similar surgery. In that trial, there were no differences in pain scores or morphine consumption between treatment groups. ${ }^{14}$ This result may be explained by the fact that the authors included heterogeneous gynecologic surgeries and supraumbilical incisions. It is known from cadaveric and observational studies that a single shot lumbar TAP block with $20 \mathrm{~mL}$ of local anesthetic is ineffective in blocking supraumbilical dermatomes., ${ }^{9,12}$ Griffiths' results may have also been influenced by block failure, as there was no description of block distribution. A significant percentage of patients included in that study were obese, a known factor for block failure, even under US guidance. In our report, we tested the somatosensory block height above the umbilicus during continuous lumbar TAP blockade in our patient with a body mass index of $40 \mathrm{~kg} \cdot \mathrm{m}^{-2}$.

Additionally, this case is interesting in the context of sensory block height with lumbar TAP blocks. For the 48 $\mathrm{hr}$ during which the infusion was running, the patient had an extensive abdominal wall block involving T6-L1 bilaterally. This observation suggests that block extension may be affected by the variables of volume and infusion time. Further, we report a slow reversal of sensory block following catheter removal. The patient reported sensory block reversal progressing caudally from T6, although the last level lost was T12. This latter finding could be linked to the final position of the catheter tip. The complete disappearance of sensory block was noted at $81 \mathrm{hr}, 33 \mathrm{hr}$ after infusion discontinuation and catheter removal. This observation supports those previously reported by Carney ${ }^{15}$ regarding the effectiveness of the TAP block $48 \mathrm{hr}$ posttotal abdominal hysterectomy. This prolonged duration may be explained by the low vascularity of the interfascial plane and the subsequent slow local anesthetic reuptake. ${ }^{15}$

In summary, US-guided TAP blocks with catheter insertion for continuous local anesthetic infusion may be an effective alternative to epidural lumbar anesthesia in patients with significant cardiovascular and respiratory comorbidities. A surprisingly dense and long-lasting sensory block of the abdominal wall was achieved with no complications. The sensory block level obtained in this case suggests that a continuous lumbar TAP block may provide effective analgesia for large abdominal incisions involving both infraumbilical and supraumbilical sites. It may be useful to consider randomized controlled trials to evaluate the safety and efficacy of continuous infusion TAP blocks $v s$ conventional treatments (epidural and PCA) for patients undergoing abdominal surgeries.

Funding None.

Competing interests None declared.

\section{References}

1. Charlton S, Cyna AM, Middleton P, Griffiths JD. Perioperative transversus abdominis plane (TAP) blocks for analgesia after abdominal surgery. Cochrane Database Syst Rev 2010; 12: CD007705.

2. Jankovic ZB, Pollard SG, Nachiappan MM. Continuous transversus abdominis plane block for renal transplant recipients. Anesth Analg 2009; 109: 1710-1.

3. Rafi AN. Abdominal field block: a new approach via the lumbar triangle. Anaesthesia 2001; 56: 1024-6.

4. Hebbard P, Fujiwara Y, Shibata Y, Royse C. Ultrasound guided transversus abdominis plane (TAP) block. Anaesth Intensive Care 2007; 35: 616-7.

5. Farooq M, Carey M. A case of liver trauma with a blunt regional anesthesia needle while performing transversus abdominis plane block. Reg Anesth Pain Med 2008; 33: 274-5.

6. Saha S, Brish EL, Boddu K. Bilateral transverse abdominis plane catheters for continuous postoperative abdominal pain relief with intermittent boluses. J Ultrasound Med 2010; 29: 855-6.

7. Heil JW, Ilfeld BM, Loland VJ, Sandhu NS, Mariano ER. Ultrasoundguided transversus abdominis plane catheters and ambulatory perineural infusions for outpatient inguinal hernia repair. Reg Anesth Pain Med 2010; 35: 556-8

8. Rozen WM, Tran TM, Ashton MW, Barrington MJ, Ivanusic JJ, Taylor GI. Refining the course of the thoracolumbar nerves: a new understanding of the innervation of the anterior abdominal wall. Clin Anat 2008; 21: 325-33.

9. Tran TM, Ivanusic JJ, Hebbard P, Barrington MJ. Determination of spread of injectate after ultrasound-guided transversus abdominis plane block: a cadaveric study. B J Anaesth 2009; 102: 123-7.

10. Hebbard P. Subcostal transversus abdominis plane block under ultrasound guidance. Anesth Analg 2008; 106: 674-5.

11. McDonnell JG, O'Donnell BD, Farrell $T$, et al. Transversus abdominis plane block: a cadaveric and radiological evaluation. Reg Anesth Pain Med 2007; 32: 399-404.

12. Shibata $Y$, Sato Y, Fujiwara Y, Komatsu T. Transversus abdominis plane block. Anesth Analg 2007; 105: 883.

13. Kato $N$, Fujiwara $Y$, Harato $M$, et al. Serum concentration of lidocaine after transversus abdominis plane block. J Anesth 2009; 23: 298-300.

14. Griffiths JD, Middle JV, Barron FA, Grant SJ, Popham PA, Royse $C F$. Transversus abdominis plane block does not provide additional benefit to multimodal analgesia in gynecological cancer surgery. Anesth Analg 2010; 111: 797-801.

15. Carney J, McDonnell JG, Ochana A, Bhinder R, Laffey JG. The transversus abdominis plane block provides effective postoperative analgesia in patients undergoing total abdominal hysterectomy. Anesth Analg 2008; 107: 2056-60. 